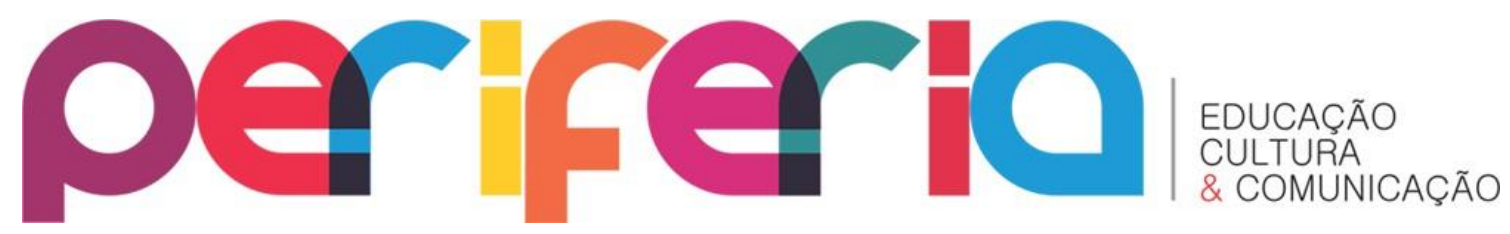

\title{
AS BONECAS KARAJÁ EM AULAS DE CIÊNCIAS: CAMINHOS PARA A IMPLEMENTAÇÃO DA LEI 11.645/08 E DIÁLOGO COM OS DIREITOS HUMANOS
}

\author{
Roberto Dalmo Varallo Lima de Oliveira ${ }^{1}$ \\ Universidade Federal do Tocantins (UFT) / CEFET-RJ \\ Glória Regina Pessôa Campello Queiroz ${ }^{2}$ \\ Universidade do Estado do Rio de Janeiro (UERJ)/ CEFET-RJ
}

\section{RESUMO}

A inserção de temas da cultura indígena está presente na Lei de Diretrizes e Bases da Educação Nacional, a partir da Lei 11.645 de 2008. Assim, as disciplinas da área científica passam a ser aliadas na busca pela construção de uma Educação que valorize a diversidade cultural brasileira. O presente artigo traz uma possibilidade de implementação da lei 11.645/2008 a partir da construção de uma estratégia didática que envolve os campos de CTS (Ciência, Tecnologia e Sociedade) e Educação em Artes. Para isso trazemos as bonecas Karajá - típicas de uma etnia da região do Tocantins - e destacamos a importância de pensar uma Educação em Ciências a partir de uma perspectiva de Direitos Humanos, com destaque ao direito indígena de praticar e revitalizar as suas tradições e costumes culturais.

Palavras-chave: Educação em Ciências, Direitos Humanos, Lei 11.645/08, Bonecas Karajá

\section{THE KARAJÁ DOLLS IN SCIENCE CLASSES: WAYS TO IMPLEMENT THE LAW 11.645/ 08 AND DIALOGUE WITH HUMAN RIGHTS \\ ABSTRACT}

The inclusion of themes of indigenous culture is present in the Law Guidelines and Bases of National Education from the Law 11.645 of 2008. Thus, the disciplines of the scientific area become allies on seeking for the building of an education that values Brazilian cultural diversity. This paper presents a possibility of implementation of the Law 11.645/2008 from the construction of a teaching strategy that involves the STS fields (Science, Technology and Society) and Education in Arts. For that we bring the

\footnotetext{
${ }^{1}$ Licenciado em Química pela UFF (2012), Mestre e Doutorando em Ciência, Tecnologia e Educação pelo CEFET-RJ (2014). Foi professor da Escola Básica e atualmente é professor da Universidade Federal do Tocantins (UFT). Seus trabalhos buscam convergência entre Educação em Ciências e Direitos Humanos tanto na realização de práticas na Escola Básica quanto na formação dos Professores de Ciências. E-mail: robertodalmo7@gmail.com

${ }^{2}$ Licenciada em Física pela UERJ (1970), Mestre em Ciências dos Materiais pelo IME (1976) e Doutora em Educação pela PUC-RJ (2000). Atualmente é credenciada no Programa de Pós-Graduação Ciência Tecnologia e Educação (PPCTE) do CEFET/RJ e professora adjunta do Instituto de Física Armando Dias Tavares da UERJ. Realiza pesquisas na área de Educação, com ênfase em Ensino e Aprendizagem de ciências, investigando e atuando principalmente nas seguintes linhas: formação de professores, ensino de física, CTS e ciência e arte. E-mail: gloriapca@gmail.com
} 


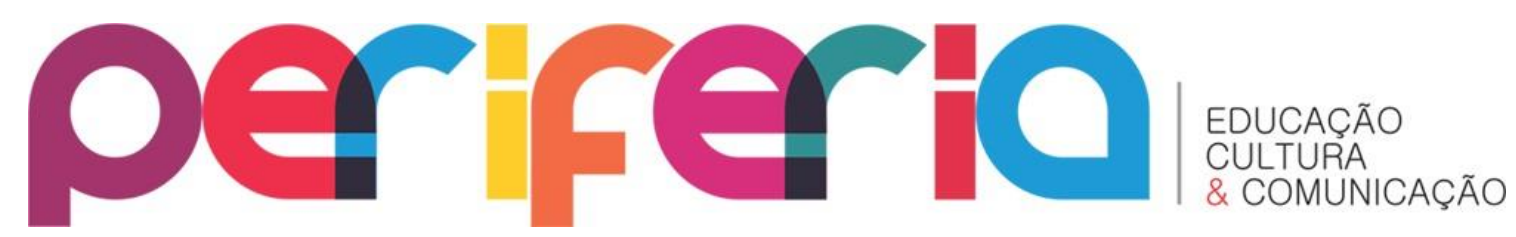

Karajá dolls - typical of an etnic group of Tocantins' region - and we highlight the importance of thinking about a Science Education from a perspective of human rights, specially the indigenous right to practice and revitalize their cultural traditions and customs.

Keywords: Science Education, Human Rigths, Law 11.645/28, Karajá dolls

\section{AS BONECAS KARAJÁ EM AULAS DE CIÊNCIAS: CAMINHOS PARA A IMPLEMENTAÇÃO DA LEI 11.645/08 E DIÁLOGO COM OS DIREITOS HUMANOS}

\section{INTRODUÇÃO}

Em uma palestra no Evento "Ciência, Tecnologia, Arte e Povos Indígenas no Brasil" o professor Gersem Baniwa ${ }^{3}$ proferiu uma frase que nos propôs reflexões sobre a educação em Ciências e a condição do indígena no Brasil: "Se todos têm o direito de mudar, por que nós temos que nos manter os mesmos?". Ir além de uma visão cristalizada do indígena é necessário, possível, e dialoga com nosso trabalho (OLIVEIRA; QUEIROZ, 2013). Nele, destacamos as possibilidades de trabalhar tópicos de Ciências (Química, Física e Biologia) em uma perspectiva de Direitos Humanos, pensando em uma estratégia didática que possibilitasse o empoderamento de sujeitos e grupos sociais postos à margem historicamente, que educasse para uma cultura do "nunca mais" às violações de direitos humanos sofridas pelos grupos ou sujeitos, mas que não deixasse de trabalhar as Ciências em seu contexto epistemológico, social e tecnológico. Dessa maneira, faremos a divisão deste artigo a partir de algumas reflexões traçadas. Iniciaremos discutindo brevemente a relevância da aproximação entre Educação em Ciências e Direitos Humanos, principalmente no que se refere aos Direitos dos Povos Indígenas. Em seguida, estruturaremos a estratégia didática CTSARTE e, por fim, construiremos um exemplo de estratégia didática a partir das Bonecas Karajá ${ }^{4}$.

\footnotetext{
${ }^{3}$ Palestra "História e Cultura dos Povos Indígenas na Escola: lei 11.645" apresentada pelo professor Gersen Baniwa durante o evento "Ciência, Tecnologia, Arte e Povos Indígenas no Brasil" realizado no Museu Ciência e Vida, em Duque de Caxias, RJ, no dia 22/03/2014.

4 Como sugestão: Viver Ciência - 1a temporada / Data de exibição: 23/06/13 Tema: Estudo da UFG auxilia no reconhecimento das bonecas Karajá como Patrimônio Cultural do Brasil / Convidados: Prof. Nei Clara de Lima (diretora do Museu Antropológico/UFG) e Prof. Telma Camargo (Faculdade de
} 


\section{periferio}

\section{A INTERFACE EDUCAÇÃO EM CIÊNCIAS E DIREITOS HUMANOS}

Em um tempo no qual a globalização e os fluxos migratórios se fazem presentes no cotidiano escolar, ampliando a necessidade de convivência, diálogo e tolerância com o diferente, a relação entre Direitos Humanos e Educação em Ciências torna-se indispensável à educação científica. Tal reflexão leva ao questionamento das diversas culturas que foram postas à margem ao longo de processos históricos. Com isso, a aula de ciências seria também um espaço de empoderamento de culturas e da explicitação de conflitos interculturais, no sentido de estimular os estudantes a um amplo debate, possibilitando a compreensão de que a luta por uma legitimação de suas identidades é também uma luta política e, por isso, a ser traçada coletivamente. Entretanto, construir uma aula de ciências que vá ao encontro dos Direitos Humanos é uma batalha contra um modelo de escola que, por possuir grande dificuldade de diálogo com as diferenças, encontrou como solução o silêncio. Seria uma luta contra os discursos do "somos responsáveis apenas pelo conteúdo de Ciências", do "não tenho tempo para isso", do "não fui formado para isso" e do "isso é responsabilidade dos professores de filosofia e sociologia". Por fim, seria uma luta contra a naturalização das constantes violações de direitos humanos. Esses fatores fazem o ato de educar para a valorização das diferenças e para a luta contra as violações de direitos humanos ser um intenso e árduo "nadar contra a corrente".

No que se refere aos povos indígenas, o Professor Gersen Baniwa em palestra mostrou que, apesar da existência da lei 11.645/08, que estabelece a inclusão de temas sobre "História e Cultura Indígena", há muito que se avançar. O palestrante destacou que é preciso superar representações estereotipadas sobre os Povos Indígenas, tais como a imagem do indígena como violento, traiçoeiro, preguiçoso, canibal, sem cultura, sem língua e sem valores. Porém, a representação que consideramos ter gerado um maior incômodo foi o apontamento da percepção geral

Ciências Sociais/UFG) / Apresentação: Brunno Favacho. Entrevista disponível em: <https://www.youtube.com/watch?v=03qCSVDnnul> 


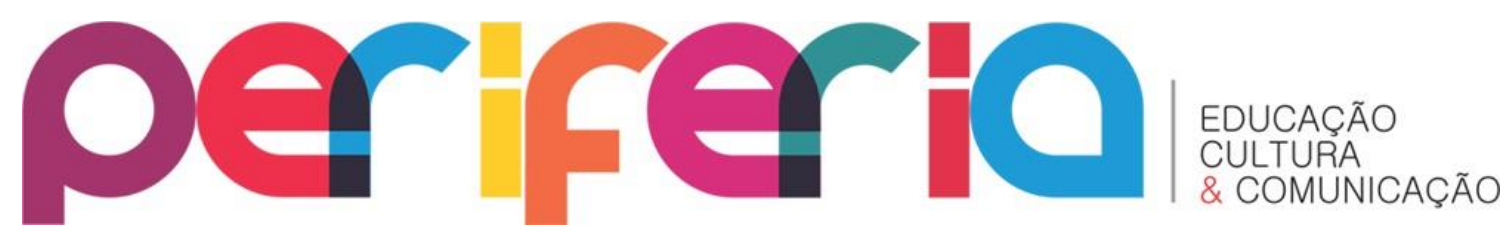

de uma cultura indígena estática. Se as culturas são dinâmicas - não são puras, nem acabadas, mas modificam-se temporalmente -, por que os indígenas são fadados a permanecerem em um imaginário colonial, sendo acusados de falsos índios se não usam cocar ou não ficam nus em suas aldeias? E, no que se refere aos artefatos indígenas, por que, no imaginário popular, são obrigados a permanecerem os mesmos? Deixarão de ser indígenas se mudarem?

Essas indagações se relacionam de maneira direta com a declaração sobre o direito dos Povos Indígenas, emitida pela ONU em setembro de $2007^{5}$, que diz, em seu Artigo 11:

1. Os povos indígenas têm direitos a praticar e revitalizar as suas tradições e costumes culturais. Isso inclui o direito em manter, proteger e desenvolver as manifestações passadas, presentes e futuras de suas culturas, como lugares arqueológicos e históricos, utensílios, desenhos, cerimônias, tecnologias, artes visuais e interpretativas e literaturas. (ONU, 2007).

O artigo deixa claro que a opção do indígena ao revitalizar tradições e costumes não deve ser alvo de discriminação. Já o Artigo 15 discorre que "Os povos indígenas têm direito a que a dignidade e diversidade de suas culturas, tradições, histórias e aspirações fiquem devidamente refletidas na educação pública...".

Dessa forma, o direito a não cristalização da cultura indígena pode ser considerado um aspecto relevante para a dignidade de um povo, e de grande importância para o trabalho em sala de aula. Além disso, a lei 11.645/08 garante o ensino de História e Cultura Indígena como transversal às disciplinas escolares. Mas, como é possível abordar esse tema em uma aula de Ciências? Para avançar nas discussões é necessário conhecer a estratégia didática CTS-ARTE.

\footnotetext{
${ }^{5}$ O texto da declaração foi antecedido pela existência de um Ano Internacional das Populações Indígenas (1993) e pela criação de um fórum permanente de discussões sobre a questão indígena (2002).
} 


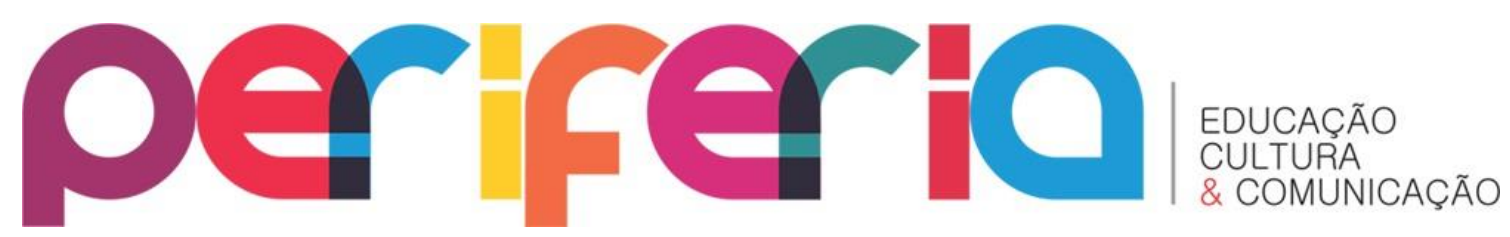

\section{CIÊNCIA, TECNOLOGIA, SOCIEDADE E ARTE: CAMINHOS INTERCULTURAIS}

As relações entre Ciência, Tecnologia e Sociedade são destacadas por uma abordagem chamada CTS que, na Educação em Ciências, busca a percepção das Ciências em seus contextos Sociais e Tecnológicos, enfatizando a compreensão das implicações éticas e políticas que permeiam a produção científica. Em convergência com a LDB 9.394/96, a abordagem CTS busca assegurar aos estudantes "a formação comum indispensável para o exercício da cidadania". Se considerarmos cidadania ${ }^{6}$ como um processo ativo de participação consciente do indivíduo ou grupo social em uma sociedade, podemos estabelecer o questionamento: uma abordagem que pretenda ampliar a compreensão da Ciência e Tecnologia em sua relação com a Sociedade será capaz de formar para a cidadania se não questionar as assimétricas relações de poder existentes na sociedade? Sem a preocupação com o empoderamento das culturas historicamente minorizadas, não estaremos apenas dando voz e poder de ação àqueles que já possuíam alguma voz? Acreditamos que sim! A subversão dessa lógica é dada a partir do momento em que nos damos conta da existência das desigualdades sociais e da necessidade de sua superação no cotidiano da educação.

Richter (2010) considera a abordagem intercultural em artes como um caminho para o trabalho com a diversidade cultural, uma vez que ela consegue envolver conceitos como cultura, identidade cultural, alteridade, universalidade e regionalismo, as igualdades e as diferenças, relativizando as situações de poder e contrastando com verdades estabelecidas. As artes possibilitam envolver temas como sexualidade, racismo, inclusão, identidades juvenis, questões de periferia, de grupos religiosos,

\footnotetext{
${ }^{6}$ Demo (1988) considera a identidade cultural como condição básica para a formação comunitária. Afirmando que "a comunidade somente reconhecerá como seu aquele projeto que, mesmo tendo vindo de fora, é capaz de revestir-se de traços culturais do grupo". Se a participação é o pilar da cidadania e as comunidades tenderão a participar quando percebem projetos de sociedade que dialogam com sua identidade cultural, como irão participar - ou interessar-se na participação - aqueles que são, a todo o momento, diminuídos culturalmente?
} 


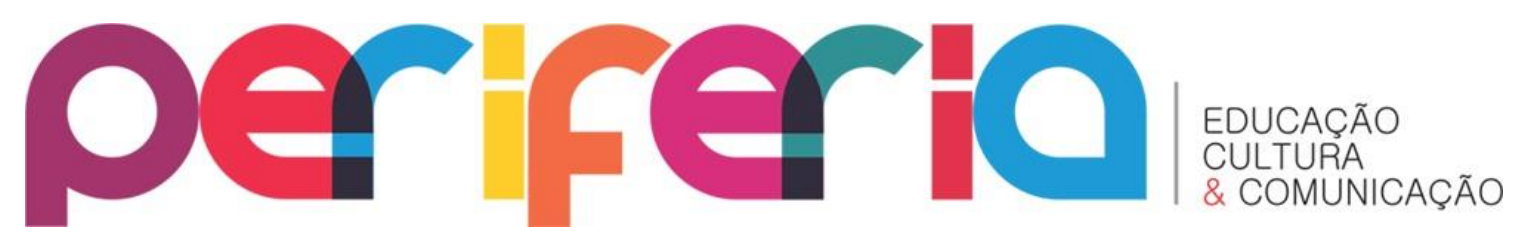

conseguindo dar voz àqueles que tiveram sua voz calada e sua imagem fadada à invisibilidade.

\section{A ESTRATÉGIA}

Consideramos o surgimento do termo CTS-ARTE como um híbrido entre os limites da abordagem CTS e os limites da Educação em Artes. A abordagem CTS proporcionaria as discussões sobre a relação entre Ciência, Tecnologia e Sociedade, já as Artes seriam responsáveis por proporcionar motivação intrínseca para embates de caráter político, social, ambiental e ideológico, possibilitando a compreensão da cultura do outro, dando voz aos excluídos e motivando tomada de posição sobre as violações de Direitos Humanos vivenciadas por determinados grupos e sujeitos. Com isso, as práticas CTS-ARTE buscam tanto partir do cotidiano do aluno, por compreender que é necessário valorizar questões nele inseridas, como introduzir elementos de belas artes ou da arte popular, para que o estudante vá além de seu próprio cotidiano e conheça outros tipos de produção de conhecimento e expressão humana.

A sequência didática que temos buscado inspira-se basicamente na proposta de Aikenhead (1994), que pensa no início de uma atividade CTS com a introdução de um tema social, seguido de uma discussão tecnológica e científica, e terminando com uma nova discussão social. Ao observar a Figura 1 é possível perceber que, assim como Aikenhead (1994), (1) buscamos o início das discussões com um tema social, porém o fio condutor das discussões é um elemento artístico que configure o tema em questão. Em seguida (2), uma tecnologia relacionada à obra de arte é introduzida; (3) estuda-se a ciência e sua relação com a tecnologia e o tema social; (4) a questão social é rediscutida à luz da ciência e da tecnologia; 5) é proposto aos estudantes que elaborem um produto final científico-artístico. 


\section{periferio}

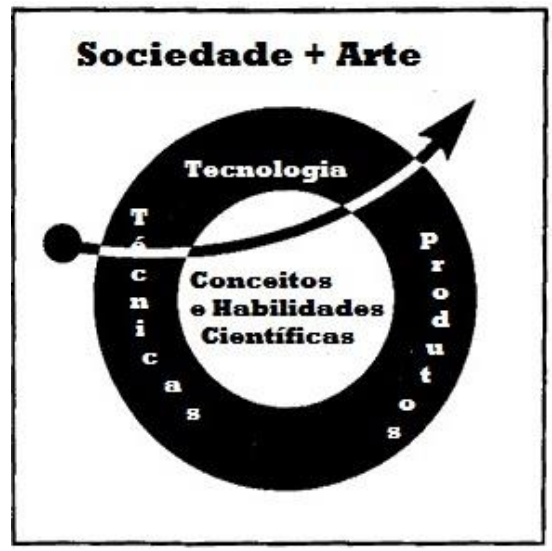

Figura 1. Proposta CTS-Arte. Adaptado de Aikenhead (1994).

Apesar da ordem sugerida, tanto no roteiro quanto no guia de elaboração, é importante ressaltar que, além da sala de aula ser um ambiente dinâmico, cada situação irá construir novos fazeres práticos que poderão ter sequências com ordenações diferentes. O tempo, o objetivo dos alunos e professores, os gostos e as vontades de cada um dos envolvidos na prática tecerão novas abordagens ou novas formas de proposição.

\section{A ESCOLHA DA ARTE + SOCIEDADE}

Além de possibilitar uma abordagem intercultural, a arte possui uma imensa relevância cultural. Ranciére (2005) afirma que "A arte sempre faz política", e que a estética transcende à própria arte. Não são feitos quadros, mas formas de vida.

Em nossa estratégia, buscamos uma arte que consiga expressar ou guiar alguma discussão de caráter social. Em trabalhos anteriores, utilizamos obras como: o documentário "O Lixo extraordinário", de Vik Muniz, por dar voz ao "catador de lixo" e considerá-lo "catador de material reciclável", mostrando sua importância na sociedade e tentando atenuar a invisibilidade social existente sobre a classe de catadores (OLIVEIRA; QUEIROZ, 2013 b); o cordel "A falta d'água no mundo" de João Batista Melo (ANDRADE, 2013), dando voz ao nordestino, mostrando as diversas reflexões que podem ser pensadas a partir dos cordéis, mas, principalmente, ao que se referia à 


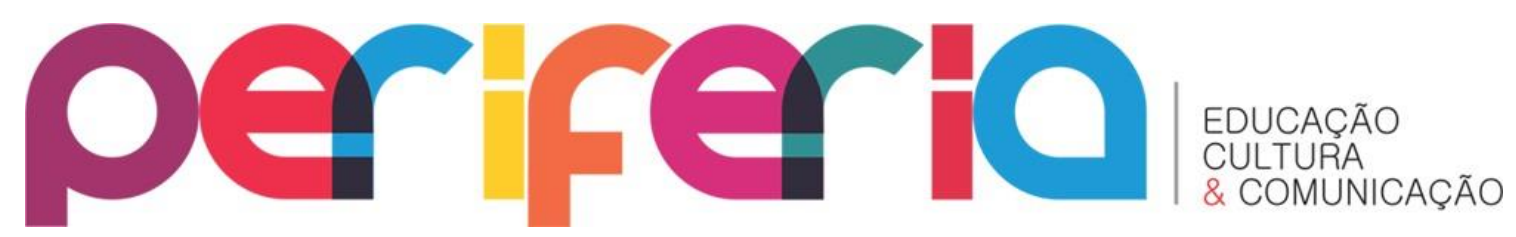

importância de uma Estação de Tratamento de Esgoto na Cidade; o filme "O Jardim de folhas sagradas", do diretor Pola Ribeiro, 2010, dando voz e empoderando o candoblecista; quadros da Frida Kahlo, colocando a mulher artista em evidência, entre outros (OLIVEIRA; QUEIROZ, 2013).

\section{A ESCOLHA DOS ELEMENTOS TECNOLÓGICOS E CIENTÍFICOS}

Os elementos científicos e tecnológicos são os principais pontos das aulas de Ciências e, por isso, devem ser tratados com sua devida importância. Qual conteúdo do currículo de Ciências consegue dar suporte às nossas discussões? Em um dos exemplos citados anteriormente (a estratégia didática que utilizou o cordel "A falta d'água no mundo"), foi abordado como tecnologia o tema das estações de tratamento de esgoto. Como conteúdo de Ciência, métodos e separações de misturas. É importante planejar a relação existente entre a discussão social, estimulada pela arte, e o conteúdo científico-tecnológico a ser trabalhado com os alunos.

\section{NOVA DISCUSSÃO E O PRODUTO FINAL}

Após a discussão inicial e a abordagem da Ciência e Tecnologia, é importante abrir uma nova discussão, estimulando os estudantes a novas reflexões. Podem ser utilizadas as estratégias de rodas de discussão, debates, júris simulados, controvérsias controladas, entre outras. Por fim, é elaborado pelos estudantes um produto que possa ser identificado como científico-artístico, podendo ser qualquer tipo de manifestação artística, como pintura, música, literatura ou teatro. Nessa etapa, a relação Sociedade-Arte através dos olhos dos estudantes, agora tendo a ciência e a tecnologia como participantes de uma nova maneira de ver o mundo, apresenta os produtos como frutos das identidades daqueles que o produziram. A abertura para diversas possibilidades de construção permitirá que haja a expressão e significação de crenças, valores e de suas posições culturais naquele dado instante. 


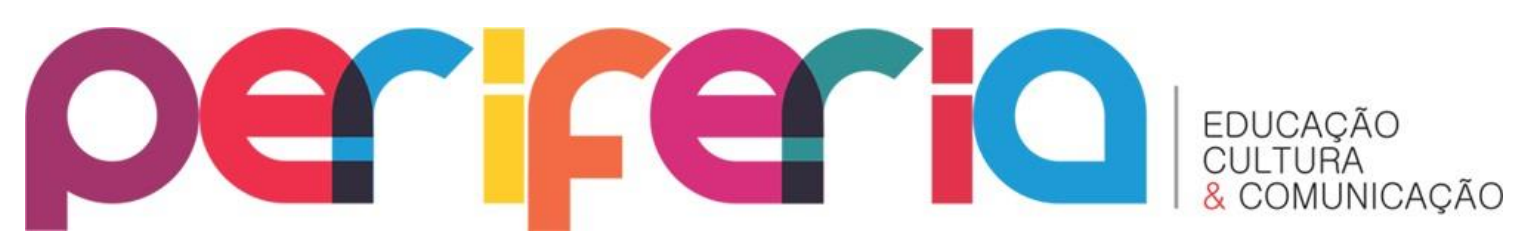

A CONSTRUÇÃO DA ESTRATÉGIA

Após pensar de forma genérica sobre a estratégia CTS-ARTE e de apresentar alguns exemplos já desenvolvidos com alunos da escola básica, trazemos um exemplo que partiu da necessidade de superação das visões distorcidas sobre os povos indígenas. Assim, as bonecas Karajá foram nosso ponto de partida.

\section{A ESCOLHA DAS BONECAS KARAJÁ}

Em 25 de janeiro de 2012, o IPHAN (Instituto do Patrimônio Histórico e Artístico Nacional) aprovou o "Oficio e os modos de fazer as Bonecas Karajá" como Patrimônio Cultural do Brasil. Para o Instituto, a confecção das figuras de cerâmica representa, muitas vezes, a única ou a principal fonte de renda das famílias Karajá. Além disso, não são consideradas apenas brinquedos, mas representações culturais Karajá que podem reproduzir o ordenamento sociocultural, explicitar mitos, rituais e a vida cotidiana. Ao brincar, a criança aprende a ser Karajá. Camargo da Silva (2013) participou do projeto "Bonecas Karajá: arte, memória e identidade indígena no Araguaia", que subsidiou o registro do artefato e, a partir de sua investigação, podemos conhecer um pouco mais sobre os Modos de fazer as Bonecas Karajá.

A lenda diz que o povo Karajá habitava as profundidades do Rio Araguaia. Porém, certo dia, um jovem Karajá encontrou uma passagem para a superfície. Ele ficou encantado com as belezas e possibilidades do local, voltou e levou outros jovens para a superfície. Ao tentarem voltar novamente, a passagem estava guardada por uma cobra, o que fez com que eles ficassem na superfície e se espalhassem ao longo do Rio Araguaia. Nas margens deste rio, as oleiras coletam os barros que, após um cuidadoso processo, dão origem às bonecas.

Camargo da Silva (2013) relata que a chamada "fase antiga" das bonecas é caracterizada por pequenas figuras com o corpo modelado em argila crua, cabelos em cera de abelha e com um formato esteatopígico (triangular e com bases largas), sem pernas e braços definidos, apenas com membros inferiores representados por formas 


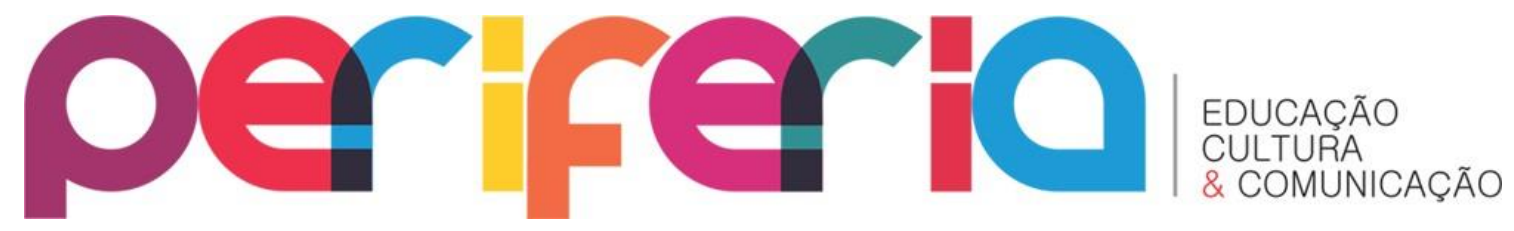

arredondadas (Figura 2). Já a fase moderna é caracterizada pela queima do objeto, modificando a forma das bonecas e possibilitando contornos mais delicados e a construção de cenas mais complexas (Figura 3).

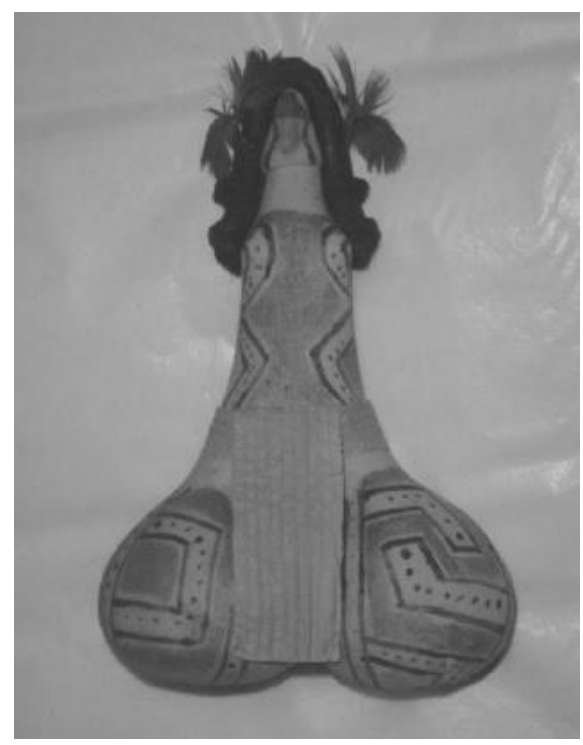

Figura 2: Boneca da fase Antiga.Foto de Véter Quirino/2005. Retirada de Camargo da Silva (2013).

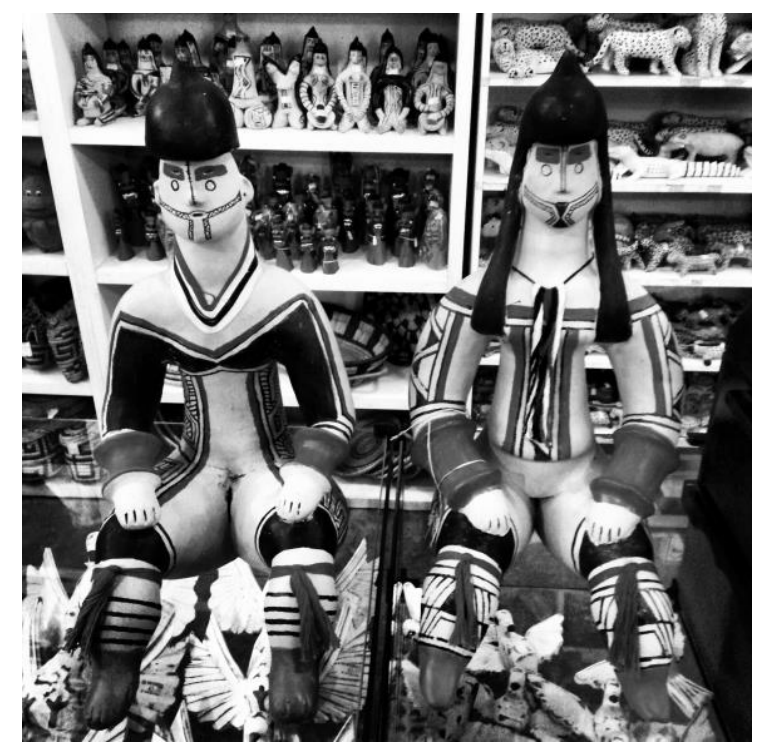

Figura 3: Boneca da fase moderna.

Foto autoral.

Ambas as bonecas ainda são produzidas. Porém, a fabricação da boneca moderna libera a criatividade e requer domínio do ofício de ceramista para tarefas como um bom acabamento, alisamento da peça, não deixar marcas de carvão quando a peça é queimada, fazer os traços da pintura de forma relitilínea, sem borrões. Em sua pesquisa, Camargo da Silva (2013) relata a presença em Santa Isabel do Morro de duas ceramistas mestras, Mahuederu e Koaxiro. Koaxiro modela tanto bonecas modernas, com pernas e braços, expressando cenas do cotidiano, quanto bonecas que constituem uma família, temática indicativo de "tradição". Já Mahuederu fabrica bonecas estilisticamente tradicionais - bonecas ocas, sem a presença de braços -, mas, também figuras mitológicas, temática das bonecas modernas. Assim, a pesquisadora afirma a existência de um trânsito entre os diferentes estilos e temáticas. Outro aspecto observado se refere à presença de atores de fora da aldeia que fazem 


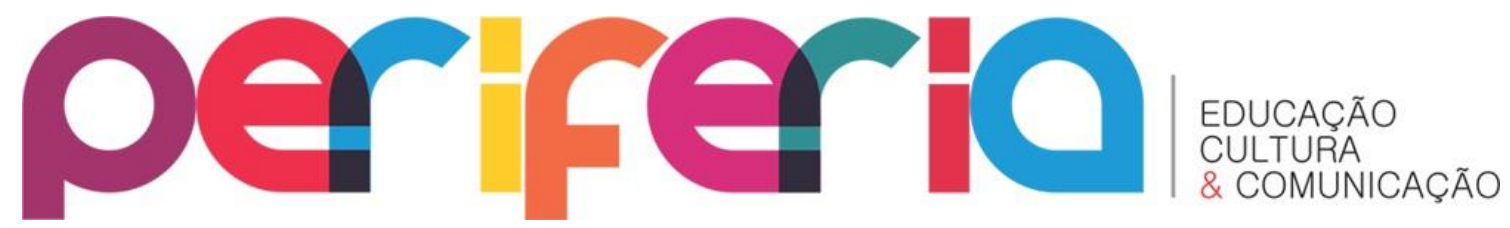

encomendas da reprodução de bonecas existentes em coleções museológicas ou instituições localizadas na Europa.

Na mesma ocasião Mahiru, outra ceramista mestra, trabalhava na confeç̧ão de uma coleção a partir de "modelos" (da fase antiga) enviados via mensagem de celular. Creheluri, seu esposo, havia baixado e arquivado as imagens das peças encomendadas na memória de seu celular para serem reproduzidas em barro. (CAMARGO DA SILVA, 2013 p. 9)

Duas concepções de tradição estão presentes: de um lado, é possível perceber que a tradição é reapropriada e reinventada a partir de um conhecimento coletivo (Figura 4); por outro lado, há a o conceito de tradição veiculada por não-índios e associada aos objetos pertencentes a coleções musealizadas, datadas no passado (Figura 5).

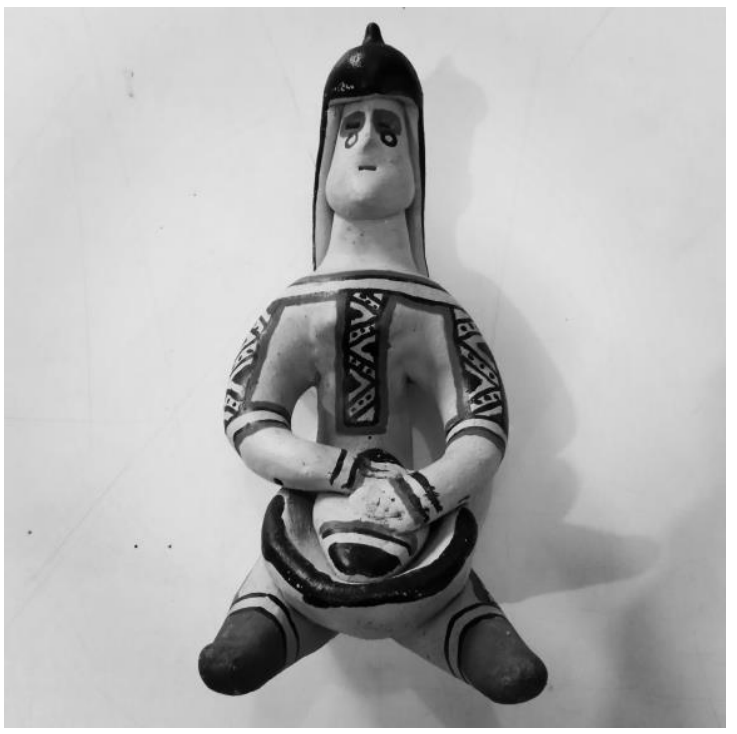

Figura 4: Boneca da fase moderna - Foto autoral.

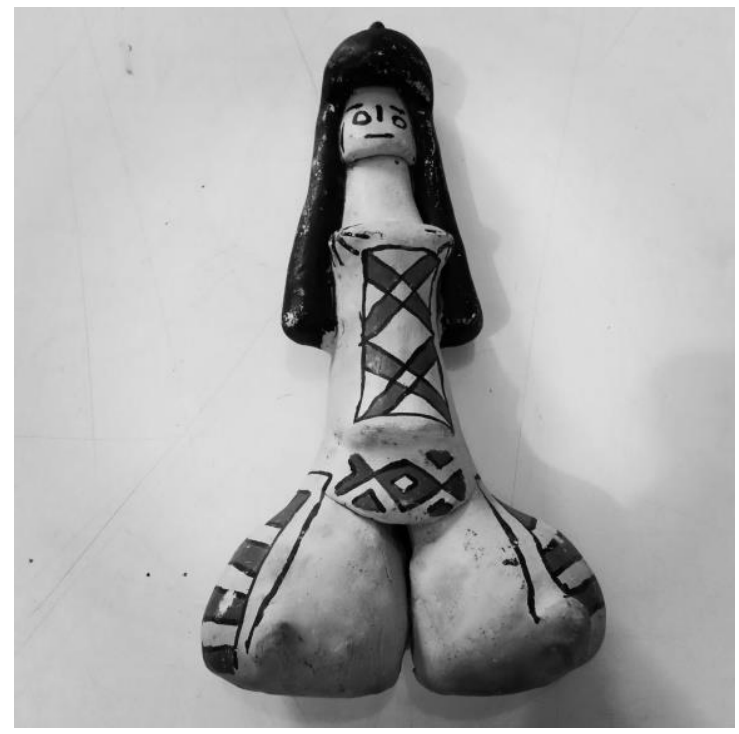

Figura 5: Boneca com estética de fase antiga - Foto autoral.

As imagens e a compreensão do processo de produção possibilitam uma comparação técnica e estilística das Bonecas Karajá, de forma que contribua, através do diálogo em sala de aula, para a construção de uma imagem mais ampla sobre a cultura indígena. Percebendo modificações nos modos de fazer, materiais e estilos, discutindo os conceitos de tradição e refletindo sobre como o diálogo entre indígenas 


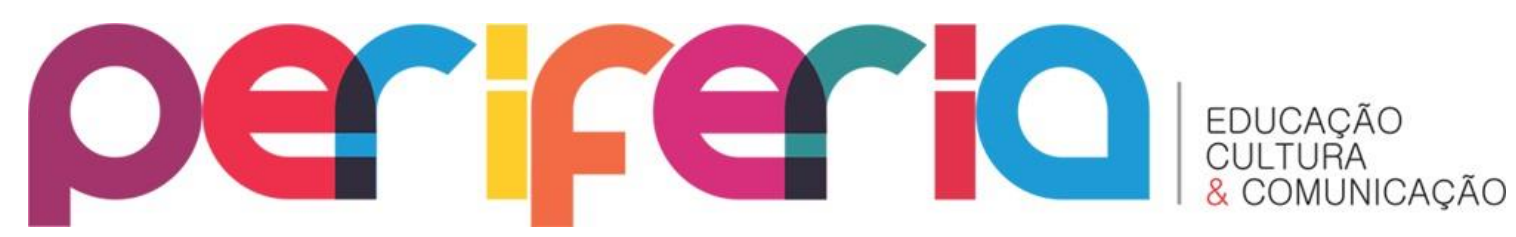

e não indígenas tecem o novo, avançamos na tentativa de desconstruir a imagem "colonial" do indígena, dando ênfase na percepção da cultura como movimento, e na não existência de uma cultura pura ou acabada.

\section{RELAÇÕES POSSÍVEIS}

O documento "PCN +" de Ciências da Natureza, Matemática e suas Tecnologias (BRASIL, 2002), complementar aos Parâmetros Curriculares Nacionais (BRASIL, 1998), dá ênfase à compreensão das transformações que ocorrem nos processos naturais e tecnológicos em diferentes contextos encontrados na Atmosfera, Hidrosfera, Litosfera e Biosfera. Assim, como elemento da Litosfera considerado a principal matéria prima da produção das Bonecas Karajá, falaremos um pouco sobre a Argila e suas transformações Físicas e Químicas.

Muitos anos antes de tornar-se objeto de estudo da Química, a cerâmica estava presente na vida dos mais diversos povos. Caçadores e agricultores já modelavam recipientes de barro que ficavam secos e endurecidos quando expostos ao sol. Em um momento posterior, percebeu-se que o fogo poderia contribuir dando formas e tonalidades aos objetos de cerâmica. Simões (2009) nos conta um pouco do processo de confecção da boneca em argila a partir da modelagem, quando a escultora se senta sobre uma esteira com uma bola de argila em mãos e uma vasilha com água ao lado. Assim, a escultora confere forma ao corpo da boneca, adicionando a cabeça, os membros e seus utensílios. Com os dedos umedecidos, retoca as peças até que fiquem da forma desejada e, em seguida, coloca as bonecas para secar ao sol ou, em períodos chuvosos, dentro da maloca, na proximidade do fogo. Quando ficam secas, elas são postas ao redor das chamas e aquecidas de um lado, viradas por pedaços de madeira ou barro, ficando a um palmo do chão, para aquecerem por igual. Com o passar do tempo, são aproximadas cada vez mais da fogueira. Outro processo relatado acontece quando as oleiras cospem na peça e, pelo chiar da saliva, conhecem seu grau de aquecimento. 


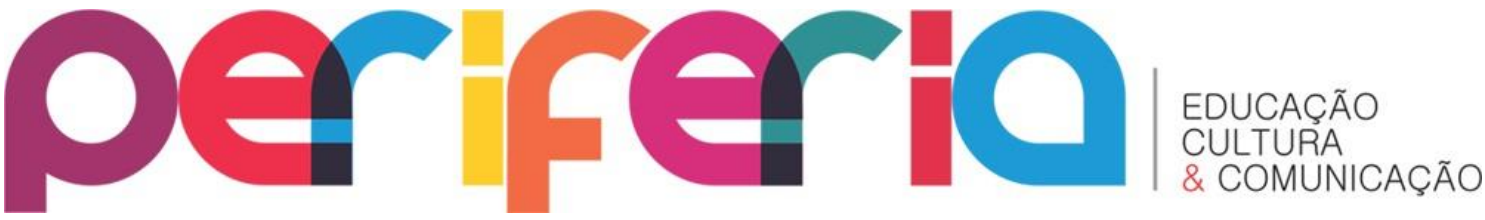

[...] sobre e sob elas colocam, então, achas de lenha acesas, deixando-as inteiramente envolvidas pelas labaredas, para que recebam calor uniforme. As peças permanecem queimando por uma a duas horas, dependendo do seu tamanho, e, à medida que esquentam, mudam de cor, chegando à incandescência, ocasião em que são retiradas do fogo e deixadas ao ar livre, para esfriarem lentamente. (SIMÕES, 1992, pp. 20-21)

Perceber o grau de aquecimento a partir do chiar da saliva é um saber da ceramista. Um saber apreendido na prática, no contato e diálogo com as ceramistas mais velhas no processo de aprendizagem e de sua formação como Ceramista Mestra. Podemos relacionar esses saberes populares com explicações científicas? Acreditamos que sim, desde que exista um respeito, por parte do professor de ciências, aos saberes populares. É preciso que o professor compreenda os dizeres de Paulo Freire... "não há saber mais ou saber menos: há saberes diferentes". Na intenção de estabelecer diálogos entre os saberes, buscaremos compreender um pouco mais sobre as argilas e suas propriedades.

\section{AS ARGILAS E SUAS PROPRIEDADES}

Argilas são uma gama de materiais compostos principalmente de silicatos de alumínio hidratados que formam uma pasta que pode ser moldada, seca e endurecida se for submetida a altas temperaturas. Não se encontram argilas compostas apenas de um único material. Uma análise química revela a existência de Sílica $\left(\mathrm{SiO}_{2}\right)$, formando entre 40 e $80 \%$ da matéria prima e Alumina $\left(\mathrm{Al}_{2} \mathrm{O}_{3}\right)$ formando entre 10 e $40 \%$. Também se encontra um teor de até $7 \%$ de Óxido Férrico $\left(\mathrm{Fe}_{2} \mathrm{O}_{3}\right)$, sendo o principal responsável pela sua coloração avermelhada, e outros óxidos como: Óxido de Cálcio (CaO), Óxido de Magnésio ( $\mathrm{MgO})$, Óxido de Sódio $\left(\mathrm{Na}_{2} \mathrm{O}\right)$, Óxido de Potássio $\left(\mathrm{K}_{2} \mathrm{O}\right)$, Anidrido carbônico $\left(\mathrm{CO}_{2}\right)$ e Anidrido Sulfúrico $\left(\mathrm{SO}_{4}\right)$.

As argilas apresentam propriedades importantes como a Plasticidade, a Retração e o enrijecimento quando expostas a temperaturas elevadas. A Plasticidade pode ser percebida quando pegamos um pouco de argila e a apertamos. O corpo 


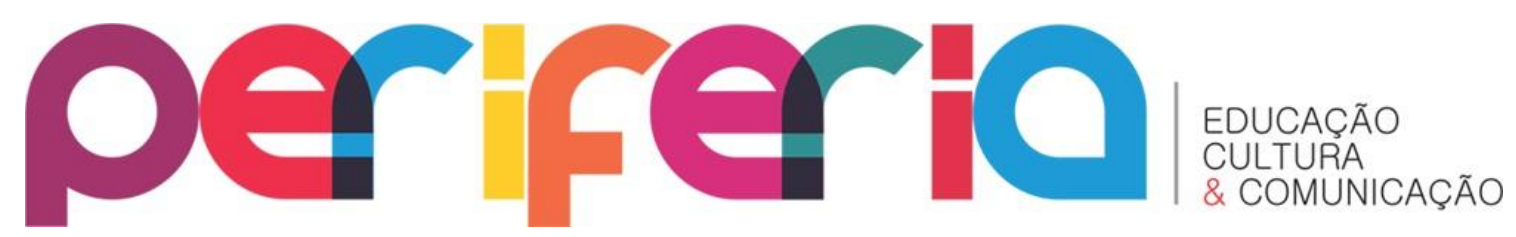

(argila) é deformado e, quando a força sobre ele (a mão amassando) cessa, a deformação é mantida. É possível perceber que essa propriedade varia de acordo com a quantidade de água presente no material. Dessa forma, a argila seca não possui elasticidade, ou seja, capacidade de ser voltar à forma anterior. Também fica fácil perceber que o aumento da temperatura diminui a plasticidade, uma vez que diminui a quantidade de água presente na argila.

A Retração é percebida por uma diminuição das dimensões da argila quando seca. Fazendo uma pequena suposição de uma situação na qual pegamos uma pequena quantidade de argila e damos a ela a forma de uma esfera, poderemos perceber que ao final do processo de secagem ela será uma esfera com dimensões menores. Isso ocorre porque a água presente na parte mais externa da esfera irá evaporar e, com o passar do tempo, a água presente na parte mais interna da esfera migrará por capilaridade para partes mais externas, mantendo a argila homogênea em relação à quantidade de água em sua estrutura. Onde havia água fica um espaço vazio, fazendo com que a esfera se retraia.

Por fim, é importante destacar o efeito do aumento de temperatura sobre a argila. O aquecimento entre 20 e 150 C faz a argila perder apenas água de capilaridade e amassamento. Entre 150 e 600 C a argila perde a água absorvida e ganha rigidez. A partir dos 600 C inicia-se a desidratação Química, assim, a argila perde água de constituição e, em seguida, há queima de matérias orgânicas. 0 segundo estágio é a calcinação de carbonetos, sendo transformados em óxidos. 0 último estágio se inicia acima de 950 ㄷ C e nele ocorre a vitrificação, processo pelo qual forma-se uma pequena quantidade de vidro que fornece dureza e torna o conjunto mais resistente e compacto.

É possível perceber que, em diferentes temperaturas, temos diferentes processos que podem ser interpretados a partir de nossos aparatos culturais: a linguagem Física e Química. Assim, percebemos a relevância do forno na revitalização das Bonecas Karajá. 


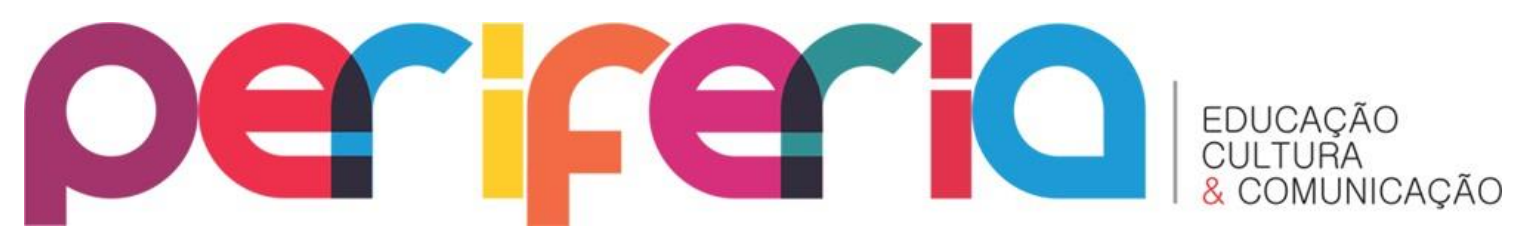

\section{O FORNO E A RELAÇÃO CIÊNCIA, TECNOLOGIA E SOCIEDADE}

Podemos representar as relações existentes entre Ciência, Tecnologia e Sociedade por um sistema complexo de mútua interação entre os elementos da tríade. Assim, é possível perceber que a Ciência contribui na modificação/construção da Tecnologia e da Sociedade, porém, também é modificada/construída por elas. Por outro lado, a Tecnologia contribui na modificação/construção da Ciência e da Sociedade, mas por elas é modificada e construída. Por fim, a Sociedade constrói/modifica a Ciência e a Tecnologia, assim como é modificada e construída por elas. E esse processo tem marcas interculturais ao longo da história da humanidade.

Ao refletir sobre o eixo da tecnologia, utilizaremos o que Osório (2002) chama de enfoque sistêmico. Essa perspectiva considera a tecnologia como um ente complexo e independente que inclui materiais, artefatos, energia, bem como os agentes que a transformam. Assim, o autor afirma que "a partir desta perspectiva, o fator chave para o desenvolvimento da tecnologia seria a inovação social e cultural, que envolve não só referências tradicionais do mercado, mas também os aspectos organizacionais e do âmbito dos valores e cultura" (p. 11).

Com essa definição de tecnologia, podemos pensar sobre a Boneca Karajá e seu modo de produção artesanal. Poderemos compreender o forno, utilizado para submeter a argila das bonecas a uma temperatura elevada, como uma tecnologia que contribuiu na construção de um novo padrão estético para a Boneca Karajá. A utilização do forno também fez com que as ceramistas mestras desenvolvessem técnicas para lidar com o fator temperatura, como mostra Simões (1992), ao relatar que a ceramista percebe a temperatura da argila através do chiar da saliva. A possibilidade de uma nova estética também modificou a relação das comunidades com a Boneca - enquanto a estética antiga possuía a função de recreação e aprendizagem sobre o "ser" Karajá, a estética moderna, além dessas funções, tornou-se fonte de renda de integrantes da comunidade. O desenvolvimento de híbridos entre as estéticas mostra uma busca de valorização do conhecimento tradicional, porém, como 


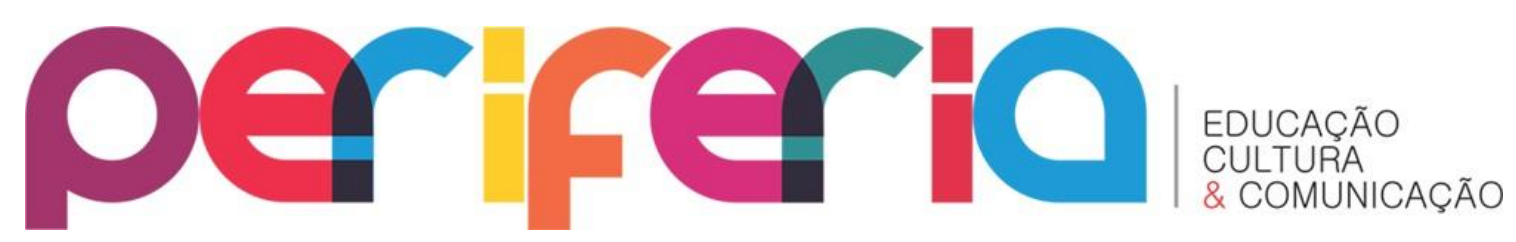

retrata Camargo da Silva (2013), essa é uma produção dada pela relação dos indígenas com os não-índios, uma vez que os indígenas fazem bonecas também sob encomenda.

\section{DISCUSSÕES}

O espaço para discussões durante o desenvolvimento das atividades é dedicado ao protagonismo dos estudantes, podendo ocorrer como júri simulado, controvérsias controladas, roda de discussões, etc. Como sugestão para um tema-debate, acreditamos ser interessante a utilização de notícias como:

O MPF (Ministério Público Federal) em São Carlos, interior de São Paulo, solicitou em caráter liminar à Justiça Federal a suspensão das atividades e o bloqueio de bens de uma empresa de materiais de construção e de seus sócios. O MPF pediu também, ao final do processo, que seja decretada a dissolução da empresa que, segundo as denúncias, causa danos ambientais por meio de extração ilegal de argila no Município de Tambaú, outra cidade do interior paulista. (PORTAL JUS BRASIL, 2013).

Com isso, teremos discussões sobre a importância da Argila em outros contextos. Prado (2011) cita que a argila tem importância na agricultura, mecânica de solos, catálise, indústria petrolífera e metalúrgica. Seria interessante dividir a turma em grupos e estimular cada grupo a pesquisar sobre o uso da argila nessas indústrias. E, assim, questionar: os impactos ambientais, existem? Qual a relação dessas indústrias com o meio ambiente?

\section{UM PEQUENO GUIA}

O planejamento dessa atividade não deve ser rígido ao ponto de esquecer as particularidades do cotidiano escolar, e nem tão fluido ao ponto que o ato de planejar seja compreendido como desnecessário. Elaboramos um guia que tem nos ajudado a pensar sobre as práticas e suas etapas. Assim, trazemos o Quadro 1 como uma fonte de consulta. 


\section{periferio}

Quadro 1: um possível guia na elaboração de um projeto CTS-ARTE

\begin{tabular}{|c|c|}
\hline Planejamento & Comentários \\
\hline Objetivos Epistemológicos & $\begin{array}{l}\text { Perceber as relações entre Ciência, } \\
\text { Tecnologia e Sociedade, principalmente } \\
\text { no que se refere ao forno na confecção } \\
\text { das Bonecas Karajá. }\end{array}$ \\
\hline Conteúdo Abordado & $\begin{array}{l}\text { Química da Terra, Argila, seus minerais e } \\
\text { processos Físico-Químicos. } \\
\text { Essa é apenas uma das possibilidades } \\
\text { que o tema desperta. }\end{array}$ \\
\hline Ambiente Educacional e Tempo didático & $\begin{array}{l}\text { O professor deverá adequar sua prática } \\
\text { ao tempo disponível, à quantidade de } \\
\text { alunos e a suas possibilidades. }\end{array}$ \\
\hline $\begin{array}{l}\text { Questões sociais + Arte escolhido para } \\
\text { abordar o tema }\end{array}$ & $\begin{array}{l}\text { Discussão sobre revitalização dos } \\
\text { artefatos culturais. Compreensão da } \\
\text { cultura indígena como mutável. } \\
\text { Bonecas Karajá }\end{array}$ \\
\hline 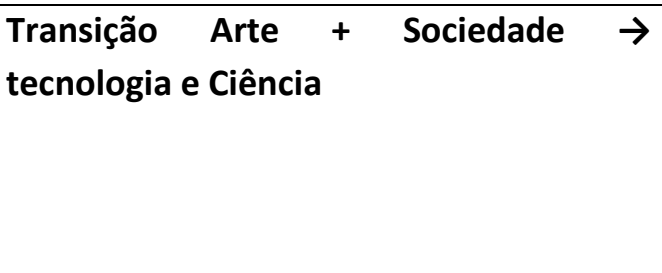 & $\begin{array}{l}\text { Qual a importância do forno na criação } \\
\text { de uma nova estética para as Bonecas } \\
\text { Karajá? } \\
\text { Quais processos Físicos e Químicos estão } \\
\text { envolvidos no aquecimento da argila? }\end{array}$ \\
\hline $\begin{array}{l}\text { Elaboração do Experimento para } \\
\text { discussão de Ciência e Tecnologia }\end{array}$ & $\begin{array}{l}\text { Por que não mexer com um pouco de } \\
\text { argila, construir objetos à escolha e } \\
\text { deixar ao sol? }\end{array}$ \\
\hline Rediscutir a questão social & $\begin{array}{l}\text { Notícia sobre extração ilegal de argila e } \\
\text { estímulo a pesquisa e discussões sobre a } \\
\text { importância da argila na indústria } \\
\text { brasileira ou presente na literatura. }\end{array}$ \\
\hline Produção dos alunos & $\begin{array}{l}\text { Construção de Bonecas Karajá e algum } \\
\text { material textual }\end{array}$ \\
\hline
\end{tabular}

Em geral, o produto científico-artístico pedido ao final da prática é uma produção livre. Porém, sugerimos que, se possível, os estudantes construam pequenas bonecas e tentem contar uma história baseada no que foi aprendido durante as aulas. 


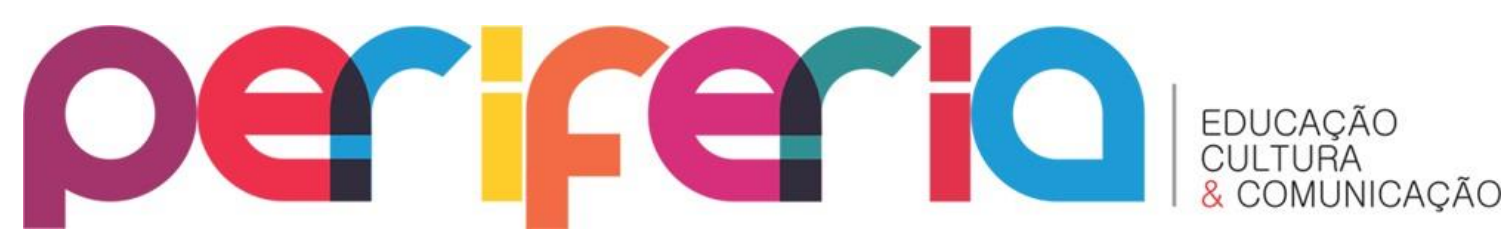

\section{REFLEXÕES FINAIS (OU INICIAIS?)}

A prática proposta busca a desconstrução de uma visão estereotipada sobre os indígenas - a visão do índio com penacho na cabeça, nu, e pertencente a uma cultura imutável. Entendemos que trabalhar a desconstrução dessa imagem se faz necessária no ambiente educacional por ser um Direito dos Povos Indígenas. A lei 11.645/08 dá suporte legal a essa prática, mas ainda há muito que ser feito e um longo caminho para ser percorrido. Entendemos essa como uma possibilidade na construção do diálogo entre a Educação em Ciências e os Direitos Humanos. Como enfatiza Morin (2003, p. 99) "não se pode reformar a instituição sem uma prévia reforma das mentes, mas não se podem reformar as mentes sem uma prévia reforma das instituições". O que estamos esperando para darmos os primeiros passos?

\section{REFERÊNCIAS BIBLIOGRÁFICAS}

AIKENHEAD, G. Educación Ciência-Tecnología-Sociedad (CTS): una buena idea como quiera que se le llame. Cidade do México, Educación química, v. 2, n. 16, p. 114-124, Abril, 2005.

AIKENHEAD, G. What is STS Science Teaching? In: SOLOMON, J., Aikenhead, G. STS education: international perspectives on reform. Teachers College Press, 1994. Disponível em: <http://www.usask.ca/education/people/aikenhead/sts05.htm>. Acesso em março de 2014.

ANDRADE, S. A. Uma abordagem CTS-ARTE nos estudos das estações de tratamento de esgoto: uma prática no ensino fundamental. 2013. 68 f. Monografia (Licenciatura) Curso de Química, Uff, Niterói, 2013.

DEMO, P. Participação é conquista. São Paulo: Cortez, 1988.

GRUN, E. Caracterização de Argilas Provenientes de Canelinha/SC e Estudo de Formulação de Massas Cerâmicas. Dissertação de Mestrado em Ciências e Engenharia de Materiais. Universidade do Estado de Santa Catarina - UDESC. Joinville, 2007.

MORIN, E. A cabeça bem feita: repensar a reforma, reformar o pensamento. Rio de Janeiro: Bertrand Brasil, 2003. 128p.

ONU. Declaração das Nações Unidas sobre os Direitos dos Povos Indígenas. New York. 13 de setembro, 2007.2 Disponível <http://pib.socioambiental.org/files/file/PIB_institucional/DECLARACAO_DAS_NACOES _UNIDAS_SOBRE_OS_DIREITOS_DOS_POVOS_INDiGENAS.pdf > Acesso em março de 2014. 


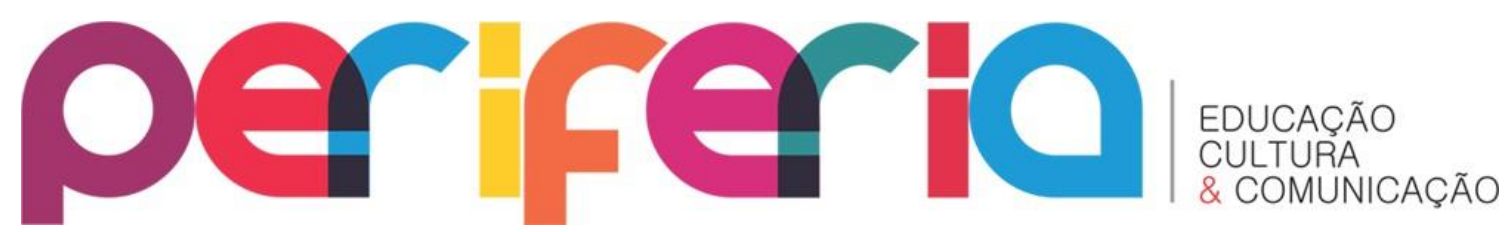

OLIVEIRA, R. D. V. L.; QUEIROZ, G. R. P. C. Educação em Ciências e Direitos Humanos: reflexão-ação em/para uma sociedade plural. Rio de Janeiro, Ed. Multifoco. 2013, $104 p$.

CTS-Arte: uma possibilidade de utilização da arte em aulas de Ciências. Niterói, Conhecimento \& Diversidade, 2013b, p. 90-98.

OSÓRIO, C. M. Enfoques sobre La tecnologia. Revista Iberoamericana de Ciência, Tecnologia, Sociedade y Innovaciión, n.2, janeiro-abril, p.1-17, 2002.

PORTAL JUS BRASIL. MPF Solicita fechamento de empresa que explora argila ilegalmente. 2013. Disponível em: http://ultimainstancia.jusbrasil.com.br/noticias/100595464/mpf-solicita-fechamento-de-empresaque-explora-argila-ilegalmente.

RANCIÉRE, J. Entrevista. Ciência e Cultura, São Paulo, vol. 57, n.4, out/ Dez. 2005. Disponível em: <http://cienciaecultura.bvs.br/scielo.php?pid=S000967252005000400011\&script=sci_arttext> Acesso em: 05 jun. 2013.

RICHTER, I. M. Arte-Educação Intercultural: pensando a realidade brasileira. In: INCLE, G. (Org.) Pedagogia da arte: entre-lugares da criação. Rio Grande do Sul, Editora UFRGS, 2010. 195p.

\section{Bibliografia Consultada}

Materiais Cerâmicos: http://www.deboni.he.com.br/ceramicos.pdf GRUN, E. Caracterização de Argilas Provenientes de Canelinha/SC e Estudo de Formulação de Massas Cerâmicas. Dissertação de Mestrado em Ciências e Engenharia de Materiais. Universidade do Estado de Santa Catarina - UDESC. Joinville, 2007. 